\title{
Kontekstualitas Dalam Perancangan Superblok Kepatihan, Kota Bandung
}

\author{
Azmi Nur Shofa1 \\ ${ }^{1}$ Program Studi Arsitektur, FPTK, Universitas Pendidikan Indonesia \\ Alamat Email penulis: azmins@student.upi.edu
}

\begin{abstract}
ABSTRAK
Permasalahan sosial seperti kemacetan yang ditimbulkan oleh mobilitas kota yang tinggi dapat menghambat efisiensi aktivitas di kota Bandung. Kemacetan mengakibatkan ruang publik kota semakin berkurang. Faktor penyebabnya adalah tingginya pertumbuhan penduduk akibat dari urbanisasi yang diprediksikan akan mencapai $60 \%$ pada 2025. Dalam aspek desain, pola tata fungsi kota yang terpisah-pisah merupakan salah satu faktor penyebabnya. Konsep superblok yang mengintegrasikan fungsi-fungsi berbeda dan menyediakan ruang publik menjadi solusi permasalahan tersebut. Penerapan konsep superblok di Kepatihan yang merupakan kawasan pusat kegiatan kota Bandung menjadi strategis untuk pengembangan kota berkelanjutan dengan konsep superblok. Perancangan superblok Kepatihan menggunakan pendekatan kontekstual. Pendekatan kontekstual dilakukan dengan menerapkan prinsip-prinsip desain yang responsif sehingga perancangan superblok dapat mempertahankan identitas kota dan selaras dengan lingkungan sekitarnya.
\end{abstract}

Kata kunci: superblok, pusat perbelanjaan, ruang publik.

\section{ABSTRACT}

Social problems such as congestion caused by high city mobility can hamper the efficiency of activities in the city of Bandung. Congestion causes city public space to decrease. The contributing factor is the high population growth due to urbanization which is predicted to reach $60 \%$ in 2025. In the aspect of design, the pattern of urban functioning is one of the factors causing it. The superblock concept that integrates different functions and provides public space is the solution to the problem. The application of the superblock concept in Kepatihan, which is the center of Bandung's city activity, is strategic for developing sustainable cities with the superblock concept. The design of the Kepatihan superblock uses a contextual approach. The contextual approach is carried out by applying responsive design principles so that the design of the superblock can maintain the city's identity and be in harmony with the surrounding environment.

Keywords: superblock, shopping center, public space. 


\section{PENDAHULUAN}

Kondisi sosial dan gaya hidup masyarakat menjadi salah satu indikator permasalahan kompleks di kota Bandung. Permasalahan sosial kemacetan yang disebabkan oleh mobilitas masyarakat yang tinggi dapat menghambat efisiensi aktivitas kota. Tingginya mobilitas kota disebabkan oleh pengaruh modernisasi dan pesatnya pertumbuhan penduduk akibat adanya urbanisasi yang tingkatnya diperkirakan mencapai $60 \%$ pada tahun 2025. Pola kota dengan zonasi fungsi yang terpisah juga menjadi salah satu faktor tingginya mobilitas di kota Bandung. Pola fungsi yang terpisah mengharuskan orang untuk berpindah. Melihat dari permasalahan tersebut maka kota Bandung memerlukan suatu kawasan yang mampu mengintegrasikan kebutuhan kota.

Kawasan Kepatihan adalah kawasan strategis untuk pengembangan kota berkelanjutan dengan konsep superblok. Lokasinya yang strategis di pusat kota yang merupakan pusat kegiatan sehingga memerlukan bangunan-bangunan fungsi utama yang mendukung kegiatan ekonomi, sosial dan budaya. Mengacu pada kebutuhan tersebut, superblok yang diperlukan adalah superblok dengan fungsi utama perdagangan dan fungsi lainnya yaitu rekreasi, hunian dan perkantoran sehingga mampu mewadahi kebutuhan kegiatan sosial, ekonomi dan budaya.

Permasalahan dalam perencanaan dan perancangan superblok (Chiara, J.D., 1987)(Bentley, I.,1985) di antaranya bagaimana pengaturan sirkulasi bagi kendaraan dan pejalan kaki di kawasan superblok agar tidak menimbulkan kemacetan lalu lintas di sekitar kawasan, bagaimana pengaturan fungsi pada bangunan serta hubungan antar bangunan dan bagaimana penyediaan serta rancangan ruang-ruang hijau untuk meningkatkan kualitas lingkungan kawasan.

Perencanaan dan perancangan superblok Kepatihan bertujuan untuk mengurangi tingkat kemacetan di lingkungan sekitar dengan menciptakan kawasan terintegrasi yang mandiri, mengembalikan fungsi ruang-ruang hijau pada kawasan serta meningkatkan kualitas lingkungan. Sasaran utamanya adalah masyarakat kota Bandung, pelaku-pelaku kegiatan dikawasan tersebut, wisatawan lokal maupun wisatawan mancanegara yang berkunjung ke kawasan serta pihak-pihak lain yang mungkin terlibat (Rencana Detail Tata Ruang (RDTR) Dan Peraturan Zonasi Kota Bandung 2015-2035).

\section{TINJAUAN PUSTAKA}

\subsection{Superblok}

Superblok secara bahasa berarti deretan beberapa gedung bertingkat dalam suatu kawasan atau area (KBBI, 2016). Secara fisik, superblok memiliki struktur yang besar, memisahkan jalan pedestrian dari lalu lintas kendaraan dan menyediakan area terlindung, dalam kasus ini hunian (Ernawati, A., 2010). Secara desain konsep superblok menggabungkan beberapa fungsi dalam satu lokasi lahan. Fungsi gabungan yang biasanya terdapat pada kawasan superblok diantaranya fungsi hunian, fungsi perdagangan, fungsi perkantoran, dan fungsi rekreasi (Elizato,2019). Setiap blok bangunan saling terhubung melalui sirkulasi pejalan kaki (Harmoni, 2019)(Lam, 2019)( Pickard, 2003).

Prinsip perencanaan superblok (Radar Planologi, 2015) adalah (1) Efisiensi lahan; (2) Pengurangan pergerakan kendaraan; (3) Penghematan penggunaan energi. Suatu kawasan dapat dikategorikan sebagai superblok jika memenuhi persyaratan tersedianya ruang bagi pejalan kaki di dalam kawasan tersebut, terdapat ruang terbuka hijau yang cukup, serta tersedia ruang manuver dan tempat parkir yang sesuai dengan standar (Radoine, 2017). 


\subsection{Kajian Tema: Arsitektur Kontekstual}

Arsitektur kontekstual adalah tema perancangan yang mempertimbangkan konteks- konteks lingkungan sekitar lokasi tapak dalam perancangannya (Soenarno, 2006). Tujuannya untuk mempertahankan identitas lingkungan dengan mengambil beberapa inspirasi dari lingkungannya agar tercipta kesan harmonis dan selaras antara bangunan dan lingkungan (Jefri, 2019). Menurut Jefri (2019) keselarasan bangunan dengan lingkungannya terlihat dari aspek fisik maupun non fisik (Arofah, dkk., 2019). Aspek fisik seperti bentuk, elemen desain (ornament), pola fasad, bukaan, dll.

Sedangkan aspek non fisik seperti fungsi, kondisi lingkungan, filosofi, dan lain-lain (Permana, dkk., 2019). Jefri (2019) juga menyebutkan bahwa arsitektur konstektual memiliki fungsi (1) Menghadirkan bangunan yang selaras dengan lingkungan karena memperhatikan dan mempertimbangkan kondisi setempat; (2) Membentuk kesan kesatuan melalui komposisi bangunan dengan keberadaan sekitarnya; Kesinambungan fisik bangunan dengan lingkungan sekitar (Arc2o.,2020)(Muther, 1955).

Kriteria pendekatan kontekstual menerapkan prinsip desain yang responsif (Bentley, 1985) sebagai berikut:

a. Permeability, yaitu akses yang mudah dan sirkulasi bagi pengguna kemana ia dapat pergi dan tidak(Permana, dkk., 2020).

b. Variety, beberapa fungsi berbeda yang terdapat dikawasan tersedia bagi seluruh pengguna.

c. Legibility, terdapat bentuk yang mudah dikenali sehingga orang tidak kesulitan dalam berorientasi.

d. Robustness, terdapat ruang-ruang temporal dimana orang dapat menggunakan ruang tersebut untuk tujuan yang berbeda

e. Richness, elemen-elemen ruang yang digunakan seperti material, susunan ruang, dll memberikan kesan sensorik dan pengalaman ruang yang kaya.

f. Visual Appropriateness, tampilan bangunan mencerminkan fungsinya sehingga tampilan bangunan mudah dikenali.

g. Personalization, interaksi antar lingkungan dan pengguna menciptakan sejauh mana orang dapat memberi "label tempat".

\section{METODE PERANCANGAN}

Pendekatan studi yang digunakan adalah metode penelitian deskriptif kualitatif. Teknik pengumpulan data adalah wawancara, observasi dan analisis dokumen. Sumber data dalam penelitian ini adalah narasumber, dokumen, dan pada lokasi di sekitar tapak Jl. Kepatihan, Kota Bandung.

Perancangan dilakukan dengan menggunakan pendekatan kontekstual karena pertimbangan lokasi tapak yang berada pada kawasan cagar budaya, sehingga mengharuskan rancangan selaras dengan konteks kawasannya. Metode ini bertujuan untuk mengungkap kondisi keadaan fakta, variabel, dan fenomena yang terjadi saat melakukan proses perencanaan dan perancangan. Metode ini meliputi pengumpulan, menganalisis, meginterpretasi data, dan diakhiri dengan pengambilan keputusan gagasan dan solusi perancangan berdasarkan hasil analisis data tersebut.

\section{HASIL DAN PEMBAHASAN}

Kegiatan utama di lokasi tapak adalah perdagangan sehingga pusat perbelanjaan menjadi fungsi utama superblok. Fungsi lainnya yaitu perkantoran yang menunjang kegiatan perdagangan dan hotel sebagai fasilitas akomodasi. Kegiatan perdagangan dapat di kategorikan sebagai kegiatan rekreasi/wisata (wisata belanja) sehingga fungsi pusat perbelanjaan dan rekreasi menjadi satu. Adapun total besaran ruang yang dibutuhkan sebagai berikut: 
Tabel 1. Besaran kebutuhan ruang

\begin{tabular}{clc}
\hline No & \multicolumn{1}{c}{ Fungsi } & Total Kebutuhan Besaran Ruang \\
\hline 1 & Perbelanjaan dan Rekreasi & $36.051 \mathrm{~m}^{2}$ \\
\hline 2 & Hunian & $4.303,8 \mathrm{~m}^{2}$ \\
\hline 3 & Perkantoran & $10.105 \mathrm{~m}^{2}$ \\
\hline \multicolumn{2}{c}{ Total } \\
\hline \multicolumn{2}{c}{ Sumber: Data peneliti }
\end{tabular}

Untuk efisiensi lahan, fungsi-fungsi tersebut dibagi kedalam dua massa bangunan. Pembagian tersebut dilakukan berdasarkan kesamaan sifat fungsi seperti terlihat pada gambar 1.

\begin{tabular}{|ll|}
\hline \multicolumn{1}{|c|}{ Sifat Bangunan } & \\
Pusat Perbelanjaan & Publik \\
Rekreasi & Publik \\
Hotel & Privat \\
Kantor & Privat
\end{tabular}

\section{Gambar 1. Sifat Banguan dan Massa Bangunan}

Sumber: Data Peneliti, 2020

Kedua massa bangunan menggunakan bentuk dasar kotak yang menyesuaikan dengan bentuk tapak. Bentuk dasar kotak ini juga menyelaraskan dengan bentuk dasar bangunan disekitar sehingga menciptakan harmonisasi dengan lingkungan sekitar seperti terlihat pada gambar 2 .
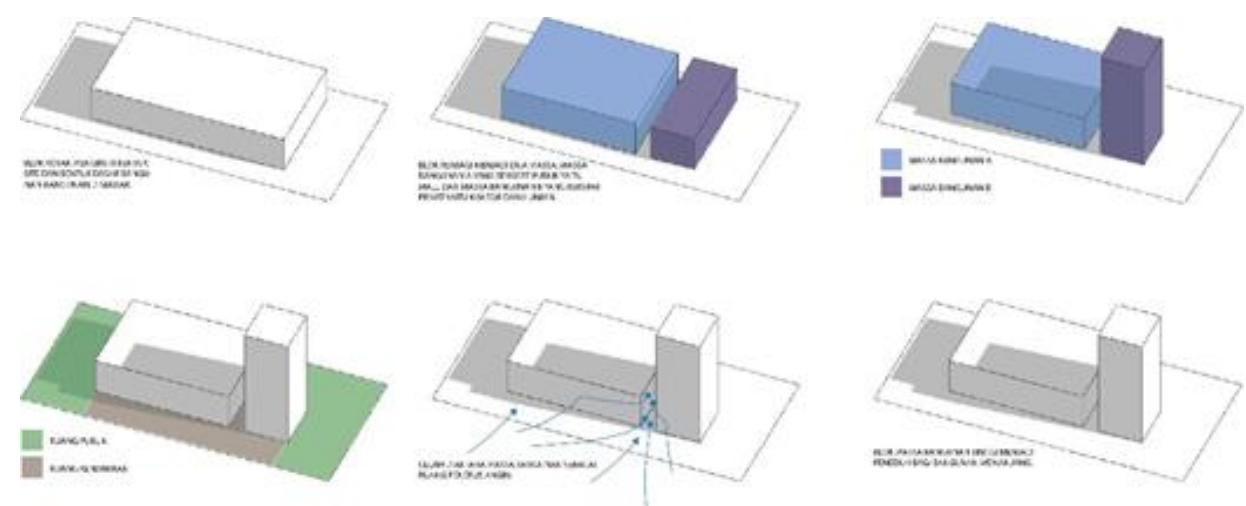

Gambar 2. Bentuk bangunan

Sumber: Data Peneliti, 2020

Bentuk dasar kotak juga digunakan untuk merepresentasikan "superblok". Kata "blok" identik dengan bentuk kotak sedangkan ukuran kotak yang memanjang dan meninggi menggambarkan kata "super". Sehingga konsep bentuk tersebut dapat menggambarkan "superblok". Perletakkan massa bangunan sesuai dengan zonasi tapak. 


\section{Azmi Nur Shofa}

Tabel 2. Luas lahan

\begin{tabular}{clccc}
\hline No & \multicolumn{1}{c}{ Sifat Fungsi } & $\begin{array}{c}\text { Perkiraan Jumlah } \\
\text { Pelaku }\end{array}$ & Persentase & Luas Lahan \\
\hline 1 & $\begin{array}{l}\text { Publik } \\
\text { (Perbelanjaan dan } \\
\text { Rekreasi) }\end{array}$ & 3924 & $70 \%$ & $13.277 \mathrm{~m}^{2}$ \\
\hline 2 & $\begin{array}{l}\text { Privat (Hunian dan } \\
\text { Perkantoran) }\end{array}$ & 1672 & $30 \%$ & $5.690 \mathrm{~m}^{2}$ \\
\hline & 5596 & $18.967 \mathrm{~m}^{2}$ \\
\hline
\end{tabular}

Sumber: Data Peneliti, 2020

Area publik ditempatkan pada area tapak yang dekat dengan tata guna lahan perdagangan agar dapat diakses dengan mudah. Untuk area privat berada dekat dengan area yang dekat dengan alun-alun agar mendapatkan view terbaik bagi fungsi hotel.

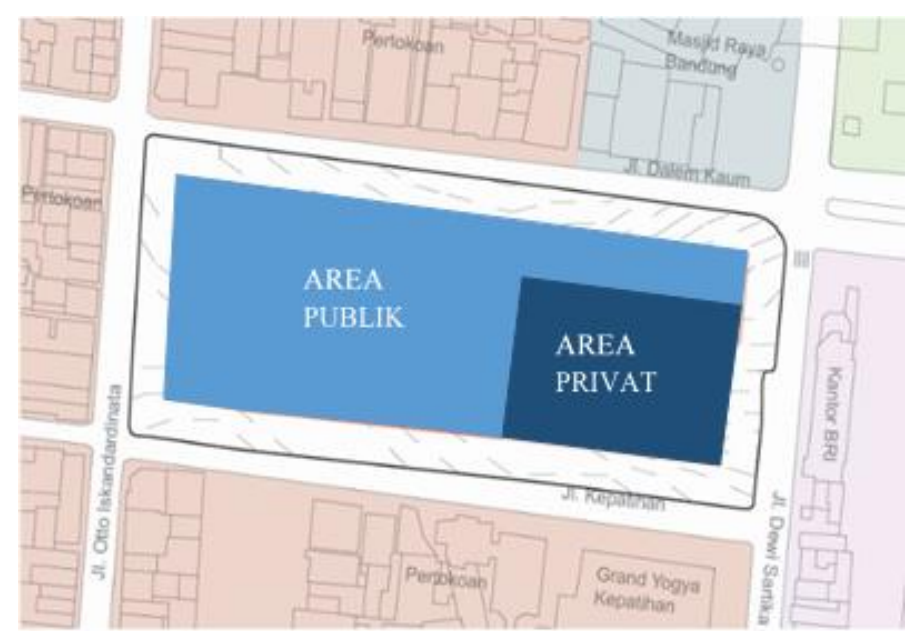

Gambar 3. Zonasi tapak

Sumber: Data Peneliti, 2020

Sistem sirkulasi tapak yang digunakan pada tapak adalah sistem sirkulasi linear yang menyesuaikan dengan bentuk tapak dan untuk mengurangi pergerakan kendaraan di dalam tapak. Akses kendaraan dari arah Kepatihan untuk meminimalisir kemacetan seperti pada gambar 4.

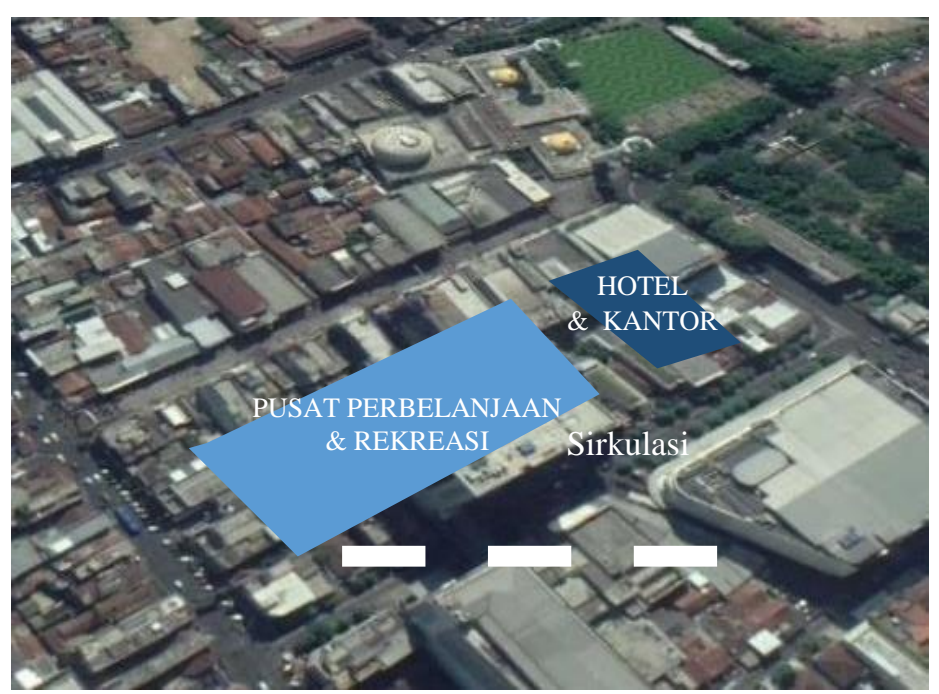

Gambar 4. Sistem sirkulasi

Sumber: Data Peneliti, 2020 
Penyediaan ruang publik bagi pengunjung terutama pejalan kaki dengan memanfaatkan area yang banyak dilewati oleh pejalan kaki. Ruang ini juga menjadi penarik pengunjung dari sekitar tapak untuk mengunjungi tapak, seperti terlihat pada gambar 5 .
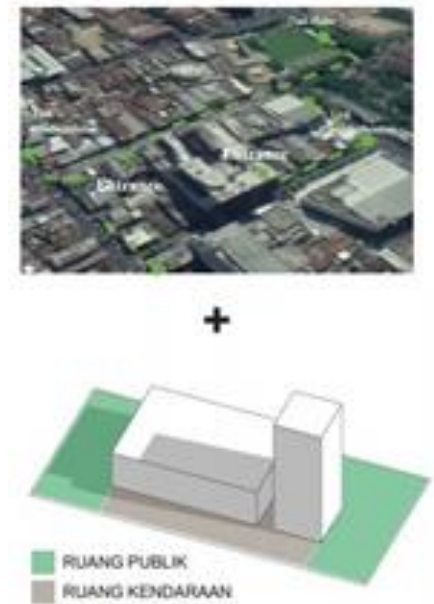
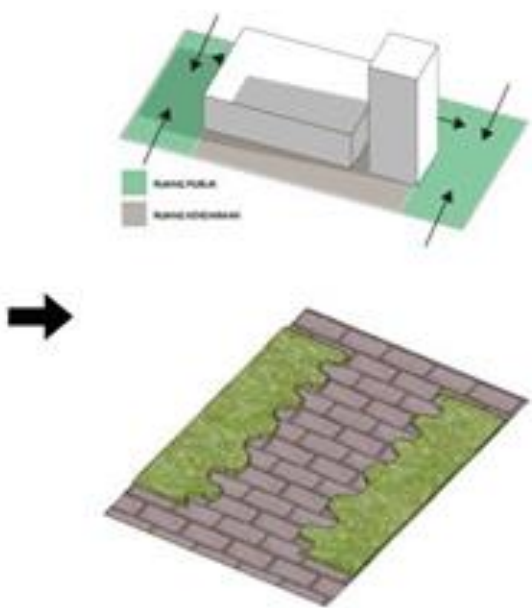

Gambar 5. Lanskap

Sumber: Data peneliti

Ruang publik dijadikan sebagai ruang hijau sekaligus ruang bagi pejalan kaki. Vegetasi disepanjang samping ruang publik berfungsi sebagai pelindung dan peneduh. Pola vegetasi yang bergelombang seperti gelombang air untuk menciptakan kesan dinamis sehingga pejalan kaki merasa senang melewati ruang tersebut (gambar 6).

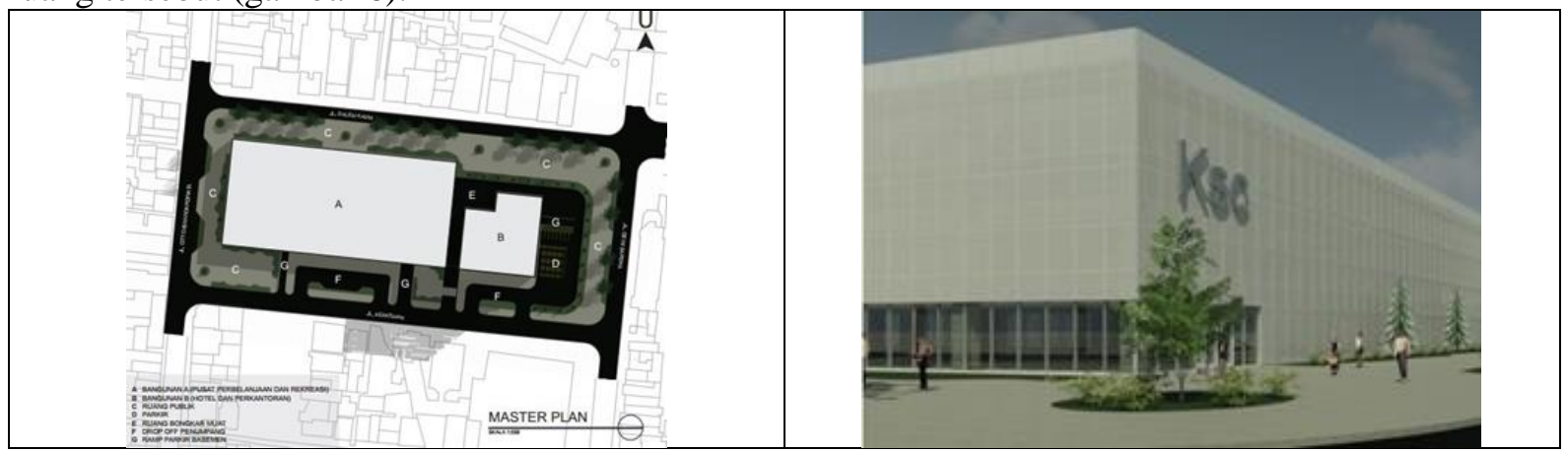

\section{Gambar 6. Master Plan}

Sumber: Data peneliti

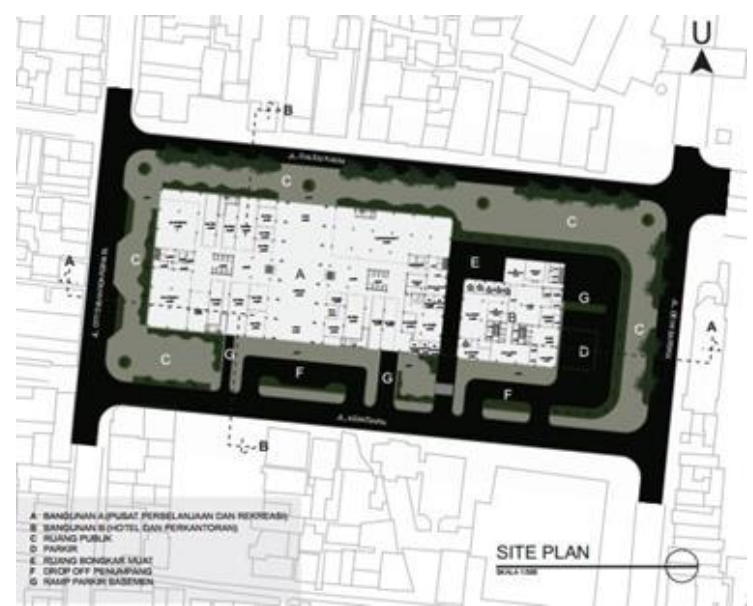

Gambar 7. Site Plan

Sumber: Data peneliti 


\section{Azmi Nur Shofa}

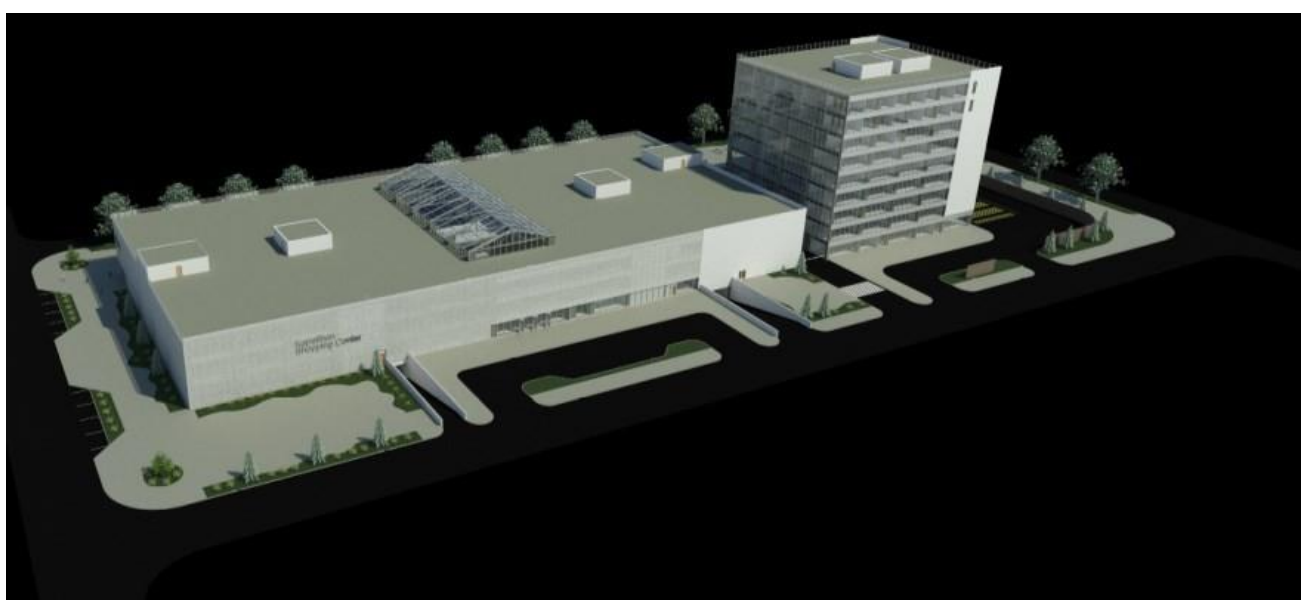

Gambar 8. Perspektif Mata Burung

Sumber: Data peneliti

Zonasi fungsi bangunan secara vertikal: letak fungsi hotel pada lantai paling atas didasari atas pertimbangan view ke luar yang baik. Sedangkan untuk fungsi rekreasi pada lantai teratas bangunan publik sebagai magnet agar pengunjung mengunjungi seluruh lantai bangunan (gambar 9).
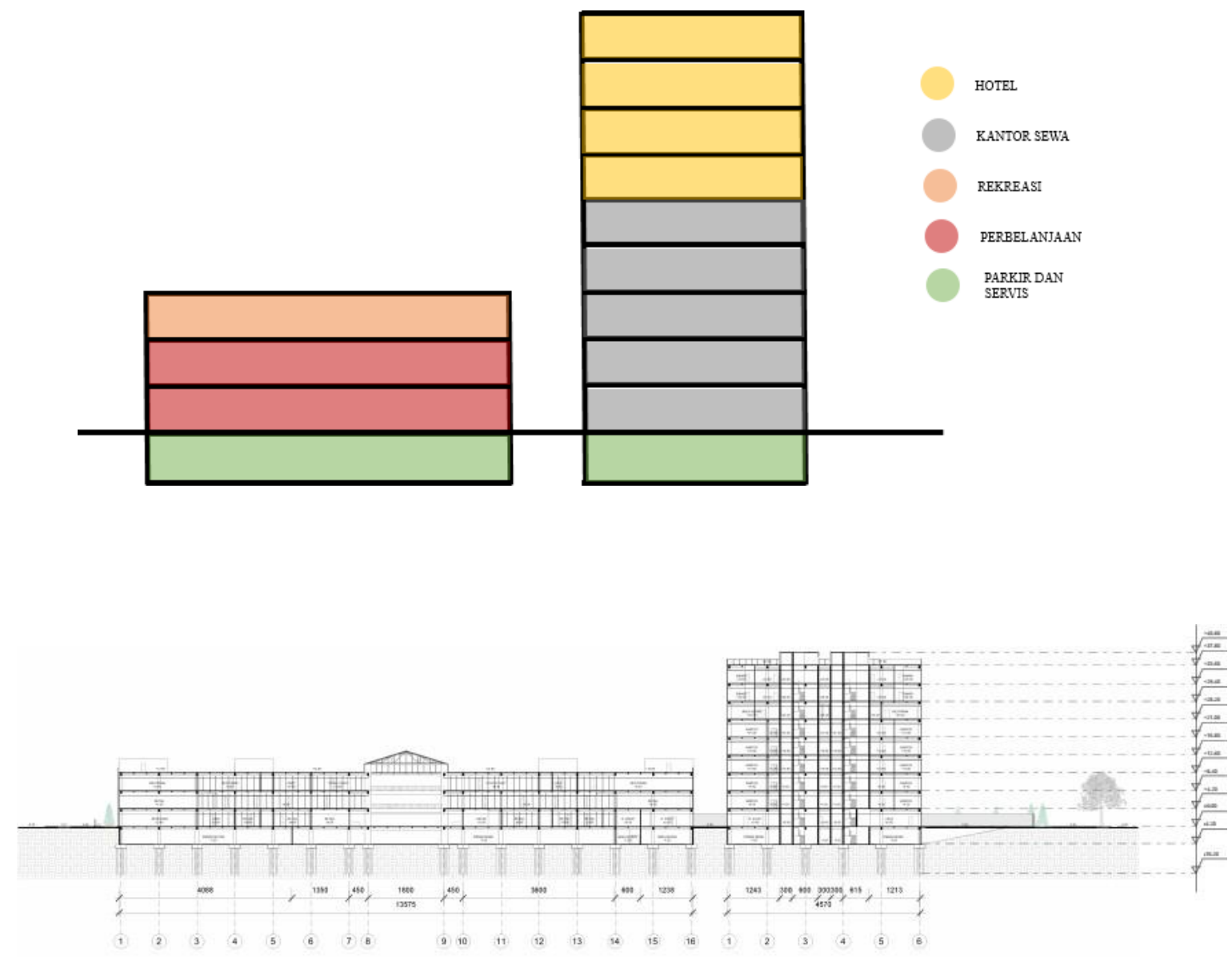

Gambar 9 Potongan Site

Sumber: Data peneliti 


\subsection{Konsep Struktur}

Kedua massa bangunan menggunakan sistem struktur rangka yang terdiri dari kolom dan balok. Ukuran grid yang digunakan adalah 9 meter dengan pertimbangan memaksimalkan ruang interior bebas kolom. Grid 9 meter untuk mendukung bentang lebar maksimal 18 meter.

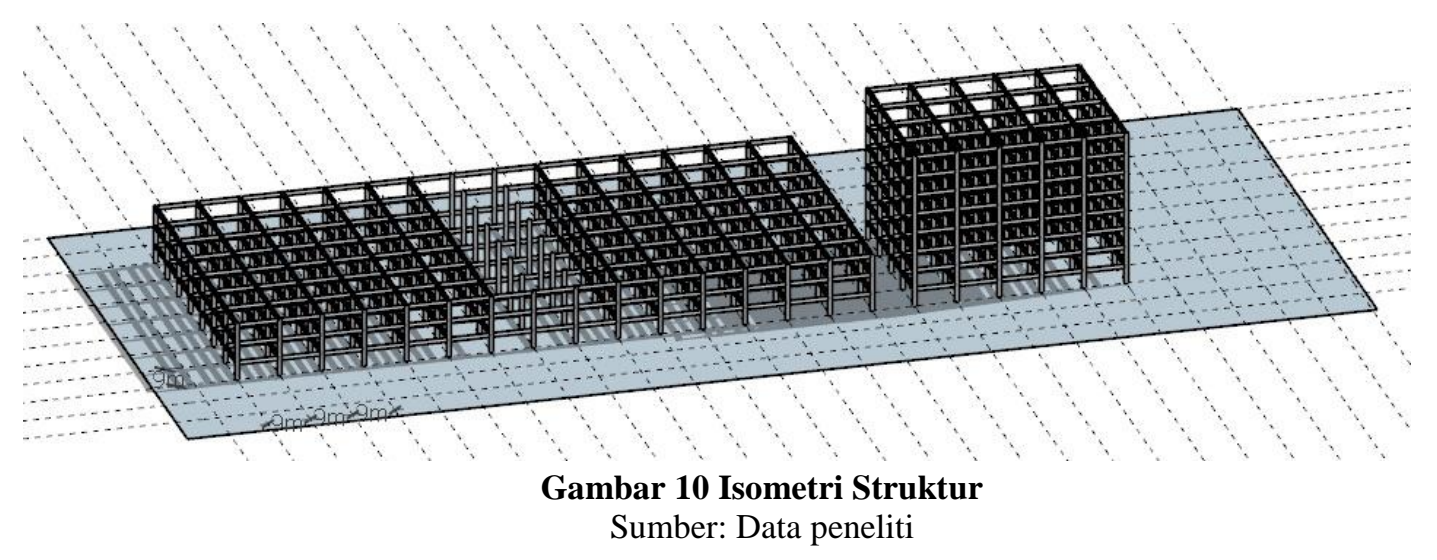

Material struktur yang digunakan adalah beton dan baja. Material beton bersifat tahan api sehingga dapat mengurangi resiko kebakaran.

\subsection{Konsep Utilitas}

- Air bersih kawasan berasal dari PDAM. Air dari PDAM ditampung di tangki penampungan kemudian dipompakan ke tangki atap setiap bangunan. Penampungan air pada tangki untuk mengantisipasi puncak kebutuhan air.

- Air kotor dari setiap lantai bangunan didistribusikan dengan memanfaatkan gravitasi menuju tempat pengolahan untuk kemudian di salurkan ke saluran kota.

- Konsep pemanfaatan air hujan pada superblok adalah untuk mengisi ulang air tanah. Pengisian ulang air tanah sangat penting untuk menjaga kelestarian air di dalam tanah. Air hujan dari atap disalurkan melalui pipa penyaluran tertutup menuju tanah.
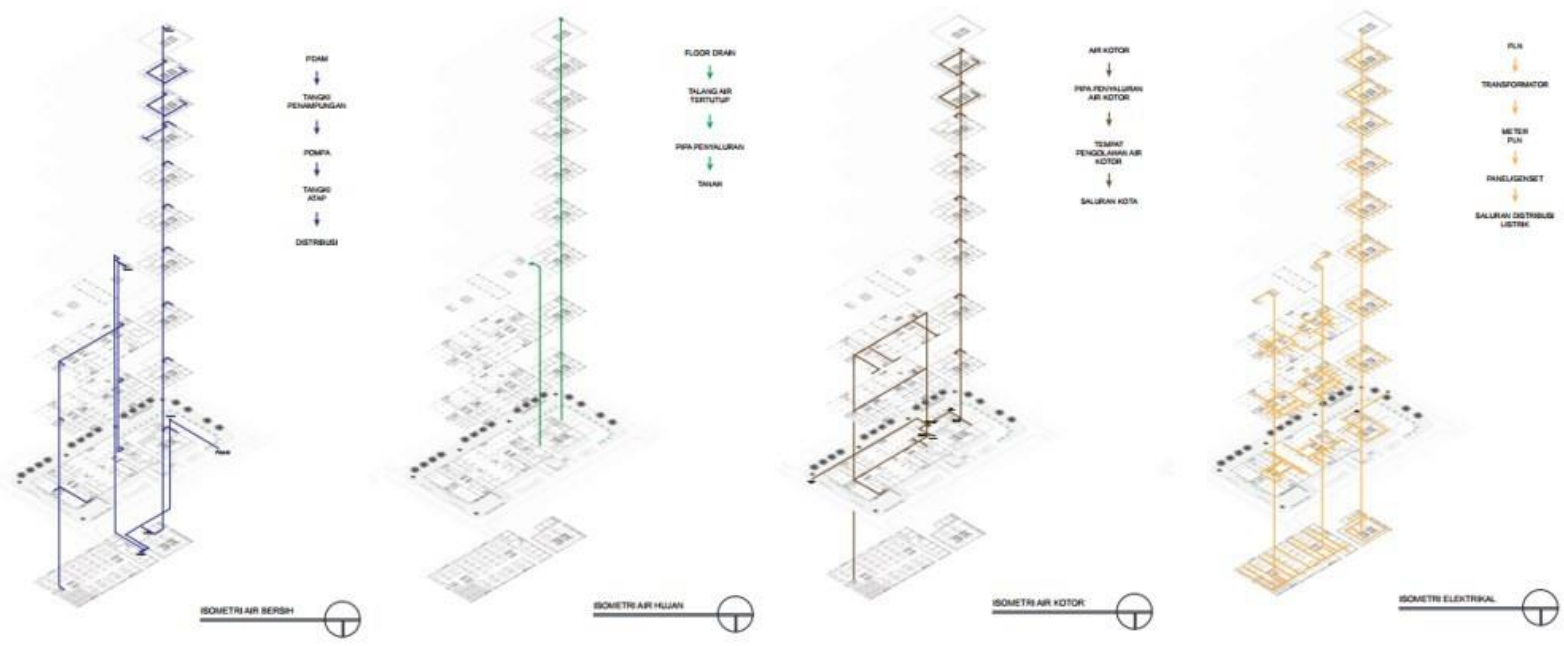

Gambar 10. Isometri Utilitas

Sumber: Data peneliti 


\section{Azmi Nur Shofa}

\section{KESIMPULAN}

Perencanaan dan perancangan superblok Kepatihan ini bertujuan untuk menciptakan kawasan terintegrasi yang mandiri, dan mengembalikan fungsi ruang-ruang publik pada kawasan. Prinsip efisiensi lahan dilakukan dengan menggabungkan dua fungsi pada satu bangunan (mixed use). Selain itu kawasan menyediakan ruang lebih bagi pejalan kaki yang juga dimanfaatkan sebagai lanskap kawasan. Penggunaan sistem sirkulasi linear agar tidak banyak aktivitas kendaraan di dalam tapak dan penempatan akses bagi kendaraan dari jalan Kepatihan untuk meminimalisir kemacetan.

Desain superblok ini menggunakan pendekatan kontekstual dengan menerapkan beberapa prinsip desain yang responsif, di antaranya:

- Permeability, dengan perletakan akses bagi kendaraan dan pejalan kaki yang mengikuti alur sirkulasi kendaraan dan pejalan kaki di sekitar tapak. Hal ini memberikan kemudahan bagi akses.

- Variety, superblok Kepatihan yang mewadahi empat fungsi berbeda.

- Legibility dan Visual Appropriateness, diaplikasikan melalui bentuk bangunan kotak memanjang dan meninggi merepresentasikan "superblok" sehingga memudahkan orang dalam mengidentifikasi bangunan. Letak bangunan yang berderet memudahkan orientasi.

\section{REFERENSI}

[1] Arc2o. (2020). Theater Design. Diakses dari https://www.arch2o.com/theater-design- basic-rules

[2] Arofah, W. R., Permana, A. Y., \& Mardiana, R. (2019). Implementation of Responsive Architectural Concepts in the Design of the Cikole Forest Resort, Bandung, West Java. Indonesian Journal of Built Environmental and Sustainability, 1(1), 1. https://doi.org/10.31848/ijobes.v1i1.247

[3] Bentley, I. (1985). Responsive Environment. London: The Architectural Press. Arsitur Media Design. (2019). Contoh Karya Arsitektur Kontekstual yang Membentuk

[4] Chiara, J.D. (1987). Time Saver for Building Types. Singapura: McGraw-Hill. Buxton, P. (2015). Metric Handbook Planning And Design Data. London:Routledge.

[5] Elizato. (2019). Contoh Struktur Organisasi Perusahaan. Diakses dari https://elizato.com/contoh-struktur-organisasi-perusahaan/

[6] Ernawati, A. (2010). Perencanaan Superblok Sebagai Model Pengembangan Pembangunan Pusat Kota Bekasi.Universitas Indraprasta PGRI.

[7] Harmoni. Diakses dari https://www.arsitur.com/2019/05/contoh-karya- arsitekturkontekstual.html

[8] Jefri, dkk. (2019). Arsitektur Kontekstual Pada Desain Bangunan. Prosiding Seminar Intelektual Muda \#1, Inovasi Ilmu Pengetahuan, Teknologi Dan Seni Dalam Perencanaan dan Perancangan Lingkungan Terbangun, 14-20.

[9] Lam, Sharon. (2019). How to Design Theater Seating.Diakses dari https://www.archdaily.com/799379/how-to-design-theater-seating-shown-through-21-detailedexample-layouts

[10] Muther, R. (1955). Practical Plan Layout. New York: McGraw-Hill Book Company, Inc.

[11] Permana, A. Y., Farah, A., Permana, S., \& Andriyana, D. (2020). KONFIGURASI RUANG BERDASARKAN KUALITAS KONEKTIVITAS RUANGAN DALAM PERANCANGAN KANTOR: SPACE SYNTAX ANALYSIS. Jurnal Arsitektur Zonasi, 3(2), 155-170. Retrieved from https://ejournal.upi.edu/index.php/jaz/article/view/25893

[12] Permana, A. Y., Susanti, I., Indra, N., Dewi, K., \& Wijaya, K. (2019). MORPHOLOGY OF URBAN SPACE : in densely populated of Bandung City. Journal of Architectural Researh and Education, 1(1), 18-35. https://doi.org/10.17509/jare.v1i1.15586

[13] Pickard, Q. (2003). Architects' Handbook. UK: Blackwell Pblishing.

[14] Radar Planologi. (2015). Perencanaan Superblock City. Diakses dari http://www.radarplanologi.com/ 2015/10/perencanaan-superblock-city.html.

[15] Radoine, H. (2017). Architecture in Context: Designing in the Middle East, First Edition. Diakses 
dari https://onlinelibrary.wiley.com/doi/boo k/10.1002/9781119173120

[16] Rencana Detail Tata Ruang (RDTR) Dan Peraturan Zonasi Kota Bandung 2015-2035. ULI. (2006). Ten Principles for Rethinking the Mall. Washington: ULI-the Urban Land Institute.

[17] Soenarno, A. (2006). Front office management. Yogyakarta : Andi. 